\title{
Autonomous third-order duffing-holmes type chaotic oscillator
}

Lindberg, Erik; Tamaseviciute, E; Mykolaitis, G; Bumeliene, S; Pyragiene, T; Tamasevicius, A; Kirvaitis, $\mathbf{R}$

Published in:

European Conference on Circuit Theory and Design, 2009. ECCTD 2009.

Link to article, DOI:

10.1109/ECCTD.2009.5275062

Publication date:

2009

Document Version

Publisher's PDF, also known as Version of record

Link back to DTU Orbit

Citation (APA):

Lindberg, E., Tamaseviciute, E., Mykolaitis, G., Bumeliene, S., Pyragiene, T., Tamasevicius, A., \& Kirvaitis, R. (2009). Autonomous third-order duffing-holmes type chaotic oscillator. In European Conference on Circuit Theory and Design, 2009. ECCTD 2009. IEEE. https://doi.org/10.1109/ECCTD.2009.5275062

\section{General rights}

Copyright and moral rights for the publications made accessible in the public portal are retained by the authors and/or other copyright owners and it is a condition of accessing publications that users recognise and abide by the legal requirements associated with these rights.

- Users may download and print one copy of any publication from the public portal for the purpose of private study or research.

- You may not further distribute the material or use it for any profit-making activity or commercial gain

- You may freely distribute the URL identifying the publication in the public portal 


\section{Autonomous Third-Order Duffing-Holmes Type Chaotic Oscillator}

\author{
Erik Lindberg, IEEE Lifemember \\ DTU Elektro Department, Electronics \& Signalprocessing, \\ 348 Technical University of Denmark, \\ Lyngby, DK-2800, Denmark \\ e-mail: el@elektro.dtu.dk \\ Gytis Mykolaitis \\ Department of Physics, Faculty of Fundamental Sciences, \\ Vilnius Gediminas Technical University, \\ Saulètekio 11, Vilnius LT-10223, Lithuania \\ e-mail: gytis@pfi.lt \\ Tatjana Pyragienè \\ Plasma Phenomena and Chaos Laboratory, \\ Semiconductor Physics Institute, \\ A.Goštauto 11, Vilnius, LT-01108, Lithuania \\ e-mail: pyragiene@pfi.lt
}

\author{
Elena Tamaševičiūtė \\ Department of General Physics and Spectroscopy, \\ Faculty of Physics, Vilnius University, \\ Sauletekio 9, LT-10222 Vilnius, Lithuania \\ e-mail: elena.tamaseviciute@ff.vu.lt \\ Skaidra Bumelienè \\ Plasma Phenomena and Chaos Laboratory, \\ Semiconductor Physics Institute, \\ A.Goštauto 11, Vilnius, LT-01108, Lithuania \\ e-mail: skaidra@pfi.lt \\ Arūnas Tamaševičius \\ Plasma Phenomena and Chaos Laboratory, \\ Semiconductor Physics Institute, \\ A.Goštauto 11, Vilnius, LT-01108, Lithuania \\ e-mail: tamasev@pfi.lt
}

Raimundas Kirvaitis

Department of Electronic Systems, Faculty of Electronics, Vilnius Gediminas Technical University, Naugarduko 41, Vilnius, LT-03227, Lithuania e-mail: raimundas.kirvaitis@adm.vgtu.lt

\begin{abstract}
A novel Duffing-Holmes type autonomous chaotic oscillator is described. In comparison with the well-known nonautonomous Duffing-Holmes circuit it lacks the external periodic drive, but includes two extra linear feedback subcircuits, namely a direct positive feedback loop, and an inertial negative feedback loop. In contrast to many other autonomous chaotic oscillators, including linear unstable resonators and nonlinear damping loops, the novel circuit is based on nonlinear resonator and linear damping loop in the negative feedback. SPICE simulation and hardware experimental investigations are presented. The Lyapunov exponents calculated from the rate equations confirm dynamical nature of chaotic oscillations.
\end{abstract}

Keywords-oscillators; nonlinear dynamics; chaotic oscillators

\section{INTRODUCTION}

Based on a well-known forced oscillator given by the second-order Duffing-Holmes differential equation $[1,2]$

$$
\ddot{x}+b \dot{x}-x+x^{3}=a \sin \omega_{1} t .
$$

Silva and Young $[3,4]$ suggested a nonautonomous circuit providing broadband chaotic oscillation with a noise-like spectrum. Low-frequency version of the oscillator has been described in detail by Kandangath [5]. The circuit diagram of the Silva-Young oscillator is sketched in Fig. 1. Later it was employed for scientific research to demonstrate the effect of resonant perturbations for inducing chaos [6,7]. A simplified version of the Silva-Young circuit (Fig. 2) was used to test the control methods of unstable periodic orbits $[8-10]$ and unknown unstable steady states [11] of nonlinear dynamical systems. The simplified oscillator is depicted in Fig. 2 and is described in detail elsewhere [12].

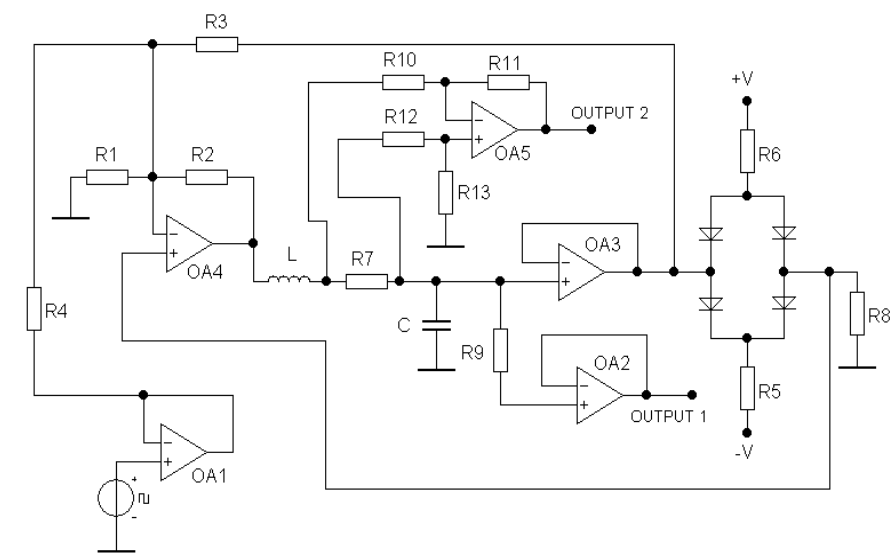

Figure 1. Silva-Young circuit: Kandangath's implementation [5]. 


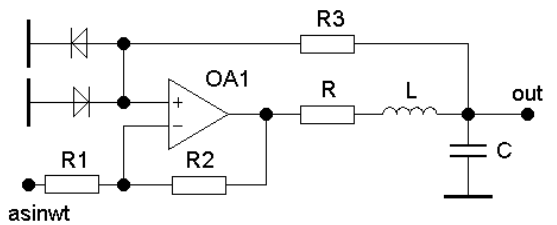

Figure 2. Nonautonomous Duffing-Holmes type oscillator [12].

The nonautonomous oscillator (Fig. 2) contains a single nonlinear positive feedback loop introduced by the resistor R3, two diodes, and the operational amplifier OA1. The external periodic drive is supplied from a sine wave oscillator.

In this paper, we suggest an autonomous oscillator which is not only a formal alternative to the classical nonautonomous Duffing-Holmes oscillator. The point is, that the externally driven chaotic oscillator has a sharp and $20 \mathrm{~dB}$ or more high peaks in the power spectrum at the drive frequency $f_{1}=\omega_{1} / 2 \pi$ and its higher harmonics [4]. While autonomous oscillator exhibits no peaks but essentially smoother spectrum. This feature may have an advantage in practical applications. The autonomous oscillator is given by the following equations:

$$
\begin{aligned}
& \ddot{x}-b \dot{x}-x+x^{3}+k z=0, \\
& \dot{z}=\omega_{f}(\dot{x}-z) .
\end{aligned}
$$

In comparison with the nonautonomous Duffing-Holmes equation the Eq. (2) lacks the external driving term $A \sin \left(\omega_{1} t\right)$. Instead it involves the third degree of freedom describing inertia of the first-order low-pass filter. Here $\omega_{\text {. }}$ is the cut-off frequency of the filter, $k$ is the feedback coefficient. Eq. (2) is equivalent to a set of three first-order equations:

$$
\begin{aligned}
& \dot{x}=y, \\
& \dot{y}=x-x^{3}+b y-k z, \\
& \dot{z}=\omega_{f}(y-z) .
\end{aligned}
$$

We emphasize in Eq. (2) an opposite sign of the damping term compared to Eq. (1). The negative damping, $-b \dot{x}$ or $+b y$ in Eq. (3) yields additional spiral instability. In Section II we propose a specific electrical circuit implementing Eq. (3).

\section{EleCtricAl CiRCUIT}

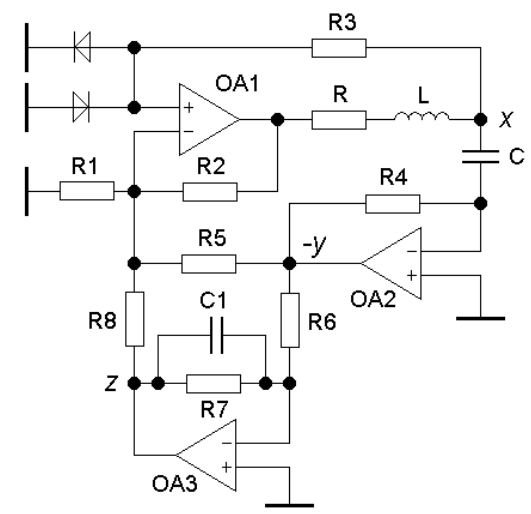

Figure 3. Autonomous Duffing-Holmes type oscillator.
The autonomous oscillator (Fig. 3) lacks the external periodic drive, but includes two additional linear feedback loops. The circuit composed of the OA2 based stage and the resistor R5 introduce the positive feedback loop, specifically negative damping. While the circuit including the OA2-OA3 stages (note a capacitor $\mathrm{C} 1$ in the latter stage) and the resistor $\mathrm{R} 8$ compose the inertial negative feedback.

\section{Simulation Results}

The circuit in Fig. 3 has been simulated using the 'Electronics Workbench Professional' software. The following element values have been used: $\mathrm{L}=19 \mathrm{mH}, \mathrm{C}=470 \mathrm{nF}, \mathrm{Cl}=20 \mathrm{nF}$, $\mathrm{R}=20 \Omega, \mathrm{R} 1=30 \mathrm{k} \Omega, \mathrm{R} 2=10 \mathrm{k} \Omega, \mathrm{R} 3=30 \mathrm{k} \Omega, \mathrm{R} 4=820 \Omega$, $\mathrm{R} 5=75 \mathrm{k} \Omega, \mathrm{R} 6=\mathrm{R} 7=10 \mathrm{k} \Omega, \mathrm{R} 8=20 \mathrm{k} \Omega$. The OA1, OA2 and OA3 are the LM741 type or similar operational amplifiers, the diodes are the 1N4148 type or similar general-purpose silicon devices. The results are presented in Figs. 4-7.
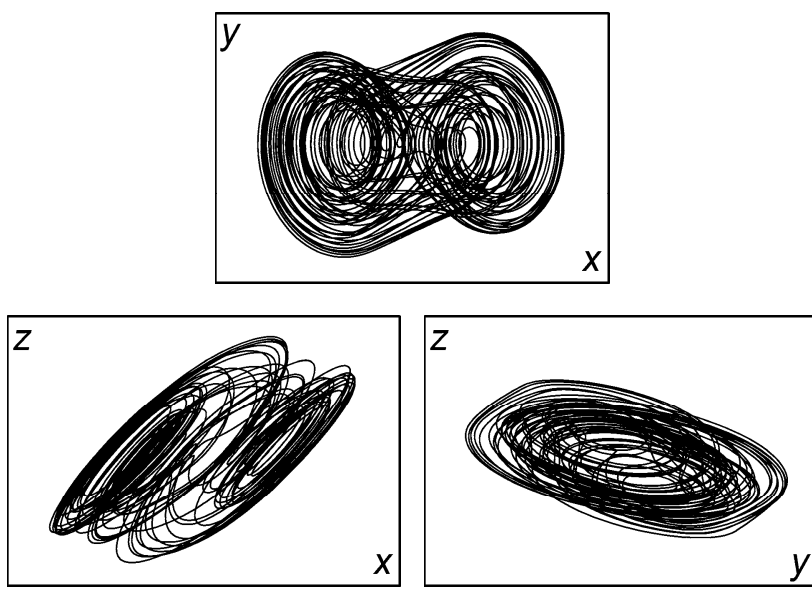

Figure 4. Simulated phase portraits.

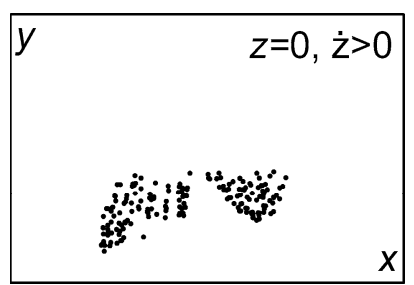

Figure 5. Simulated Poincaré section.

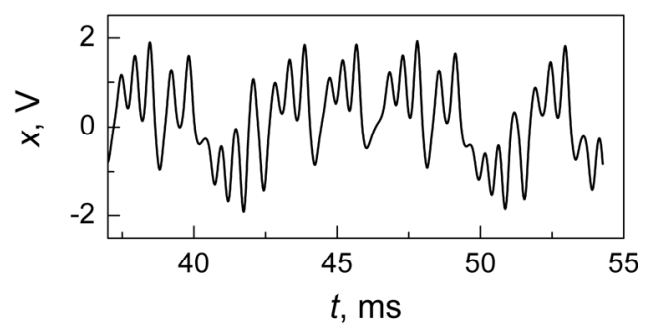

Figure 6. Snapshot of typical chaotic waveform $x(t)$. 


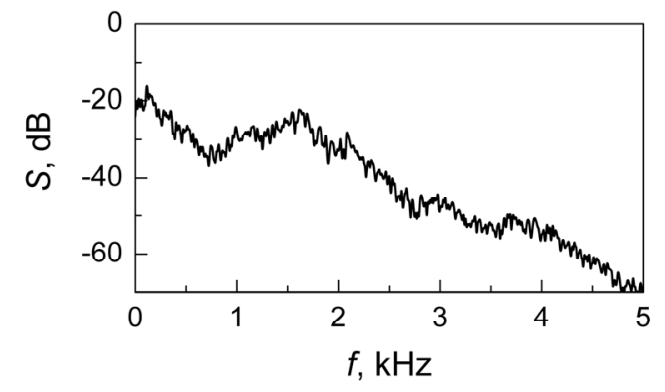

Figure 7. Simulated power spectrum $S$ from the variable $x(t)$.

\section{EXPERIMENTALRESULTS}

The autonomous oscillator has been built using the elements described in Section III, except R5 $=68 \mathrm{k} \Omega$. Typical experimental results are presented in Figs. 8-11.
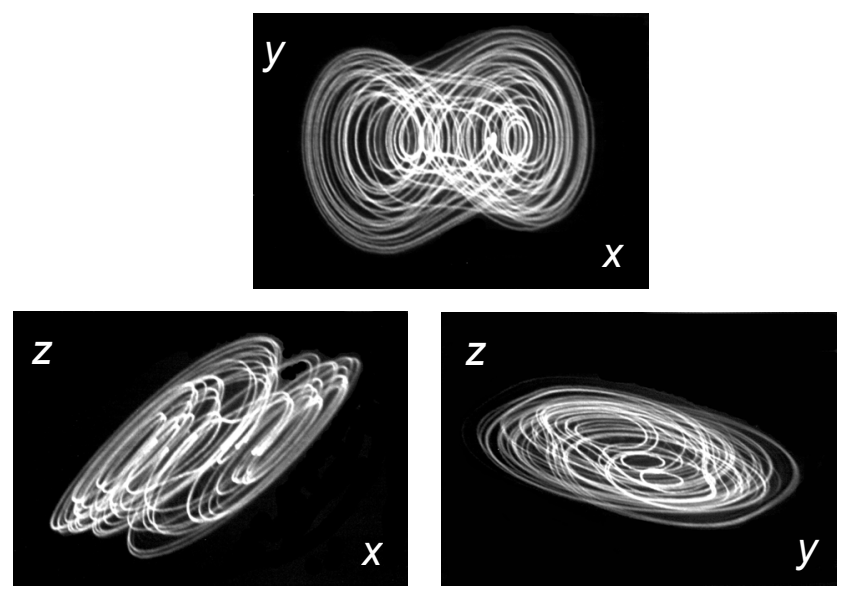

Figure 8. Experimental phase portraits.

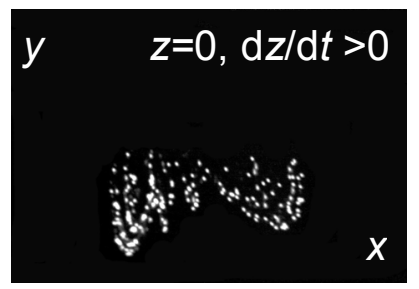

Figure 9. Experimental Poincaré section.

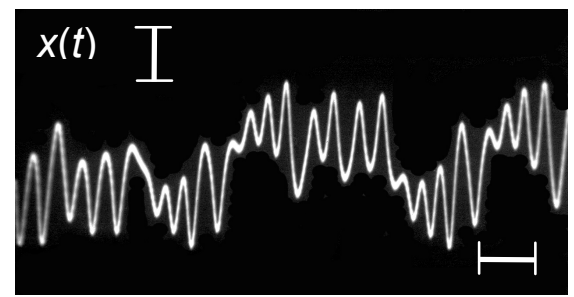

Figure 10. Experimental snapshot of chaotic waveform $x(t)$. Horizontal scale $2 \mathrm{~ms} /$ div. Vertical scale $1 \mathrm{~V} / \mathrm{div}$.

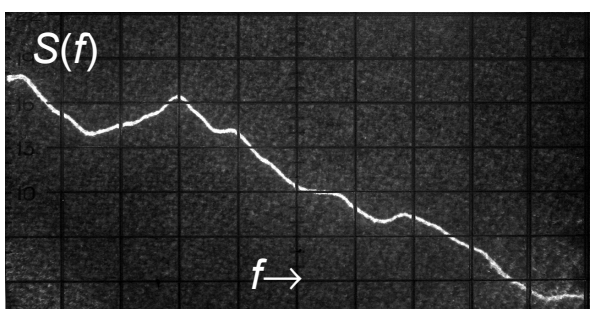

Figure 11. Experimental power spectrum $S(f)$ from the output signal $x(t)$. Frequency range 0 to $5 \mathrm{kHz}$. Horizontal scale $500 \mathrm{~Hz} /$ div., resolution $100 \mathrm{~Hz}$. Vertical scale $10 \mathrm{~dB} /$ div.

\section{CONCLUDING REMARKS}

We have designed and built a novel third-order DuffingHolmes type autonomous chaotic oscillator. In comparison with the common nonautonomous Duffing-Holmes oscillator the autonomous circuit has an internal positive feedback loop instead of an external periodic drive source. In addition, it is supplemented with an RC inertial damping loop providing negative feedback. The circuit has been investigated both numerically and experimentally. The main characteristics, including the time series, phase portraits, and power spectra have been calculated using the SPICE based software, also taken experimentally. Fairly good agreement between the simulation and the hardware experimental results is observed (Figs. 3-10). Some discrepancy (of about 10\%) between the model and the hardware prototype, namely R $5=75 \mathrm{k} \Omega$ in the model (Figs. 3-6) and $\mathrm{R} 5=68 \mathrm{k} \Omega$ in the experimental circuit (Figs. 7-10) can be explained in the following way. The inductive element in the model is an ideal device in the sense that its $L=$ const. Meanwhile the inductance of a real inductor, e.g. a coil wound on a ferrite toroidal core has a slight dependence on the current through it: $L=L(I)$.

We note that the structure of the proposed oscillator is rather different in comparison to many other third-order autonomous chaotic oscillators described so far. The basic unit of the RC Wien-bridge [13,14] and LC tank [15-17] based oscillators is the second-order linear unstable resonator. An additional degree of freedom required for chaos is introduced by supplementing the resonator with the first-order inertial nonlinear damping loop [13-17]. The same approach of building chaotic oscillators is used in higher order circuits [18-20] (some of the design principles are overviewed in a book chapter [21]). In contrast, the oscillator described in this paper contains a nonlinear unstable resonator and an inertial linear damping loop.

We do not show here the simulation results (the phase portraits, the Poincaré sections, the power spectra) from Eqs. (3) since all of them are very similar to the corresponding plots presented in Figs. (4-11). While the bifurcation diagram and the spectrum of the Lyapunov exponents are important results from Eqs. (3). For a specific set of fixed parameters, namely $k=1.6$ and $\omega_{f}=0.5$, the bifurcation diagram and the 
three Lyapunov exponents are presented as functions of the parameter $b$ in Fig. 12 and Fig. 13, respectively.

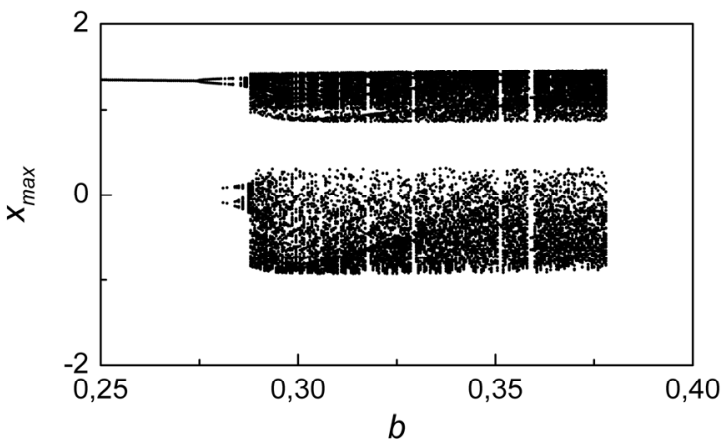

Figure 12. Bifurcation diagram: local maxima points of $x(t)$ vs. parameter $b$. Other parameters are fixed at $k=1.6$ and $\omega_{f}=0.5$.

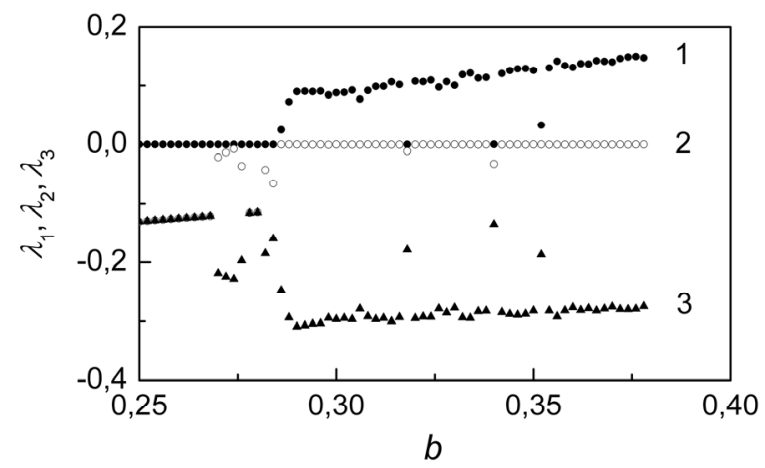

Figure 13. Lyapunov exponents vs. parameter $b$. Other parameters are fixed at $k=1.6$ and $\omega_{f}=0.5$.

Specifically, the positive value of the $\lambda_{1}$ is a direct evidence of chaotic nature of the system.

\section{REFERENCES}

[1] E. Ott, "Chaos in Dynamical Systems" Cambridge: Cambridge University Press, 1993.

[2] R.C. Hilborn, "Chaos and Nonlinear Dynamics: An Introduction for Scientists and Engineers" Oxford: Oxford University Press, 2006

[3] C.P. Silva and A.M. Young, "High frequency anharmonic oscillator for the generation of broadband deterministic noise," U.S. Patent No. $6,127,899$. October 3, 2000.
[4] C.P. Silva and A.M. Young, "Implementing RF broadband chaotic oscillators: design issues and results," Proc. IEEE Int. Symp. on Circuits and Systems, vol. 4, pp. 489-493, Piscataway, NJ: IEEE, 1998.

[5] A.K. Kandangath, "Inducing chaos in electronic circuits by resonant perturbations: Master Thesis" Tempe: Arizona State University, 2004. $<$ http://www.ecogito.net/projects/>.

[6] Y.-C. Lai, A. Kandangath, S. Krishnamoorthy, J.A. Gaudet and A.P.S. de Moura, "Inducing chaos by resonant perturbations: theory and experiment," Phys. Rev. Lett., vol. 94, no. 21, 214101, 2005.

[7] A. Kandangath, S. Krishnamoorthy, Y.-C. Lai and J.A. Gaudet, "Inducing chaos in electronic circuits by resonant perturbations," IEEE Trans. Circuits and Systems-I, vol. 54, pp. 1109-1119, 2007.

[8] A. Tamaševičius, E. Tamaševičiūtè, G. Mykolaitis and S. Bumelienè, "Stabilisation of unstable periodic orbit in chaotic Duffing-Holmes oscillator by second order resonant negative feedback," Lith. J. Phys., vol. 47, pp. 235-239, 2007.

[9] A. Tamaševičius, G. Mykolaitis, V. Pyragas and K. Pyragas, "Delayed feedback control of periodic orbits without torsion in nonautonomous chaotic systems: theory and experiment," Phys. Rev. E, vol. 76, no. 2, 026203, 2007.

[10] A. Tamaševičius, E. Tamaševičiūtè, T. Pyragienè, G. Mykolaitis and S. Bumelienè, "Extended resonant feedback technique for controlling unstable periodic orbits of chaotic system," Commun. Nonlin. Sci. Num. Simul., vol. 78, no. 12, pp. 4273-4279, 2009.

[11] A. Tamaševičius, E. Tamaševičiūtè, G. Mykolaitis and S. Bumelienè, "Switching from stable to unknown unstable steady states of dynamical systems," Phys. Rev. E, vol. 78, no. 2, 026205, 2008.

[12] E. Tamaševičiūtè, A. Tamaševičius, G. Mykolaitis, S. Bumelienè and E. Lindberg, "Analogue electrical circuit for simulation of the Duffing-Holmes equation," Nonlinear Analysis: Modelling and Control, vol. 13, pp. 241-252, 2008. <http://www.lana.lt/journal/issues.php >.

[13] A. Namajūnas and A. Tamaševičius, "Modified Wien-bridge oscillator for chaos," Electron. Lett., vol. 31, no 5, pp. 335-336, 1995.

[14] A. Namajūnas and A. Tamaševičius, "Simple RC chaotic oscillator," Electron. Lett. vol. 32, no. 11, pp. 945-946, 1996.

[15] R.A. Pikšrys, K.A. Pyragas and A.V. Tamaševičius, "Diagrams for transforming LC-autogenerator into noise generator," Radiotekhnika, no. 9, pp. 43-45, 1986, in Russian (for English translation see Telecommunications and Radioengineering, no. 9, 1986).

[16] A. Tamaševičius, "Reproducible analogue circuit for chaotic synchronization," Electron. Lett. vol. 33, no. 13, pp. 1105-1106, 1997.

[17] A. Tamaševičius, G. Mykolaitis, V. Pyragas and K. Pyragas, "Simple chaotic oscillator for educational purposes," Eur. J. Phys., vol. 26, pp. 61-63, 2005.

[18] Y. Nishio, S. Mori and T. Saito, "An approach toward higher dimensional autonomous chaotic circuits," Proc. Int. Seminar on Nonlinear Circuits and Systems, Moscow, Russia, pp. 60-69, 1992

[19] A. Tamaševičius, A. Namajūnas and A. Čenys, "Simple 4D chaotic oscillator," Electron. Lett., vol. 32, no. 11, pp. 957-958, 1996.

[20] A. Tamaševičius, A. Čenys, G. Mykolaitis, A. Namajūnas and E. Lindberg, "Hyperchaotic oscillator with gyrators," Electron. Lett., vol. 33, no. 7, pp. 542-544, 1997.

[21] E. Lindberg, K. Murali and A. Tamaševičius, "Chaotic oscillators design principles," Chaos in Circuits and Systems, eds. G. Chen and T. Ueta. World Scientific, 2002, pp. 1-21. 